Sabine Greßler, Gloria Rose, André Gazsó, Anna Pavlicek*

\section{Summary}

Titanium dioxide has been used as a food additive (E 171) in Europe since the 1960s. For a long time, it was assumed that this waterinsoluble material would not cause any negative health effects because of its low absorption rate. In recent years, however, animal studies have confirmed a dose-dependent toxic potential in the event of oral ingestion, with particular damage to the liver and kidneys, inflammatory reactions, and changes to the spleen and heart. The material was also found to accumulate in organs, and individual studies showed an effect on the intestinal flora and the immune system. One study also makes reference to a possible carcinogenic potential. The European Food Safety Authority (EFSA) rated the substance as safe when ingested orally. Up to $59 \%$ of the particles of E 171 can have a size of less than $100 \mathrm{~nm}$. On the basis of the studies available to date, the French Agency for Food, Environmental and Occupational Health \& Safety (ANSES) sees great uncertainties with regard to possible health effects, in particular because of the high proportion of nanoparticulates. The French government has therefore decided to ban $\mathrm{E} 171$ for one year starting from 01.01.2020. Consumer protection organisations are calling for the ban to be extended to the entire European Union (EU). The industry stresses that $E 171$ is safe and fears negative economic consequences. However, some confectionery manufacturers have already changed their recipes and no longer use E 171. The European Commission is changing the specifications for $E 171$ so that it may only contain a maximum of $50 \%$ of nanoparticles in the future.

${ }^{*}$ Corresponding author

\title{
Titanium Dioxide as a Food Additive
}

\section{Introduction}

Titanium dioxide $\left(\mathrm{TiO}_{2}\right)$ is a water-insoluble inorganic compound that has been produced in the form of a white powder for more than 100 years. It is used for a variety of applications but mainly as a white pigment, for example for paints and varnishes, plastics, paper, packaging materials, printing inks, cosmetics, and as a food additive. In nature, $\mathrm{TiO}_{2}$ occurs in three crystal forms: anatase, rutile and brookite. Only the first two are of economic interest and approved as food additives in the EU. The NanoTrust Dossier no. 33 provides an overview of the production methods for $\mathrm{TiO}_{2}$ and its applications. ${ }^{1}$

$\mathrm{TiO}_{2}$ has been approved as a food additive in the USA since 1966 and in Europe since 1969², and is used as a white dye or to make colours appear shinier for a wide variety of foods (e.g. chewing gum, cake icing, sugar coatings on pastries, candies, mozzarella, etc.). $\mathrm{TiO}_{2}$ has no nutritional or physiological benefit.

This dossier provides an overview of the legal regulations and research results on the health risks of $\mathrm{TiO}_{2}$ as a food additive, particularly in the context of the one-year ban in France since 01. 01.2020 .

\section{Legal regulations}

In the EU, food additives must be labelled on the packaging with a so-called "E number". If a food contains $\mathrm{TiO}_{2}$ as an additive, it must be identified with the number $\mathrm{E} 171$. $\mathrm{TiO}_{2}$ can also be used as an anti-caking agent in food production. If anticaking agents are used during the production process, but remain present in the food only in technically unavoidable traces and no longer have any effect, they are legally considered processing aids and do not have to be labelled. ${ }^{3}$

In the EU, food additives are regulated by Regulation (EC) No. 1333/2008 and only those listed in the annexes to the regulation may be used. E 171 is listed in Appendix I, Class II (food colours without maximum quantity limits) and can be applied quantum satis ("as much as necessary, as little as possible") to almost all foods. No ADI value ("acceptable daily intake"; recom- mended daily dose, i.e. the amount that can be ingested on a daily basis over a lifetime without an appreciable health risk) has been specified for $\mathrm{E}$ 171. In the USA, $\mathrm{TiO}_{2}$ has been approved as a food additive up to a maximum concentration of $1 \%$ by weight of the food. 4

With Regulation (EU) No. 231/2012, the European Commission established specifications for E 171. It may essentially only consist of pure anatase and/or rutile titanium dioxide which may be coated with no more than $2 \%$ aluminium oxide $\left(\mathrm{Al}_{2} \mathrm{O}_{3}\right)$ and/or silicon dioxide $\left(\mathrm{SiO}_{2}\right)$ in order to improve the technical properties of the product. Maximum quantity limits have also been set for the levels of contamination by toxic heavy metals and metalloids (cadmium, antimony, arsenic, lead, mercury).

The European Food Safety Authority (EFSA) proposes to limit the proportion of nanoparticles (see below) below $100 \mathrm{~nm}$ to $50 \%$ in relation to the number of particles and to introduce these parameters into the specifications for $E 171$ in Regulation (EU) No. 231/2012 ${ }^{10}$. In addition, the EFSA recommends further new information in the specifications: Firstly, titanium dioxide (E 171) as a food additive can contain small quantities $(<0.5 \%)$ of agents to control particle growth and the crystallization phase (aluminium oxide, sodium or potassium in combination with phosphate). Secondly, the particles of $E 171$ must not feature any surface modification/treatment or coating. The corresponding amendment to Annexes II and III of the regulation by the European Commission is still pending.

\section{Consumer exposure to E 171}

The amount of $E 171$ consumers take in with their daily food depends heavily on their consumption behaviour and eating habits. The estimated exposure for the US population is $1-2 \mathrm{mg} / \mathrm{kg}$ body weight per day for children under 10 years of age and approximately $0.2-0.7 \mathrm{mg} / \mathrm{kg}$ body weight/ day for the other consumer groups. For the UK population, the realistic estimates are on average 2-3 $\mathrm{mg} \mathrm{TiO}_{2} / \mathrm{kg}$ body weight/day for children under 10 years of age and $1 \mathrm{mg} / \mathrm{kg}$ body weight/ 
day for the other consumer groups. As a result of their higher consumption of sweets, children take in an average of two to four times more E 171 per day than adults ${ }^{5}$. In the Netherlands, exposure was estimated by experts from the $\mathrm{Na}$ tional Institute for Public Health and the Environment (RIVM) using information from industry. The estimate is $1.4 \mathrm{mg} / \mathrm{kg}$ body weight/day in children and $0.5 \mathrm{mg} / \mathrm{kg}$ body weight/day in people over 70 years of age. ${ }^{6}$

The EFSA estimates the maximum exposure of children (from infants to 9-year-olds) to range from 0.4 to $10.4 \mathrm{mg} / \mathrm{kg}$ body weight per day on average, for adults (18 to 64 years) from 0.6 to $6.8 \mathrm{mg} /$ $\mathrm{kg}$ body weight/day, and for people aged 65 and over from 0.4 to $4.5 \mathrm{mg} / \mathrm{kg}$ body weight/day. ${ }^{7}$

A study of 89 different foods in the USA showed the highest $E 171$ content (measured as titanium) in powdered doughnuts at $100 \mathrm{mg}$ per serving. ${ }^{5}$ In general, sweets and baked goods such as chewing gum, chocolate and products with white icing or sugar toppings contained the most E 171. Chewing gum in the form of coated tablets with a hard outer coating also had the highest titanium concentrations, as did confectionery products with hard outer shells or coated peanuts. Custard powder and instant beverage powder also had higher concentrations. Dairy products such as cheese, mayonnaise and spray cream contained only low concentrations of titanium. Many products contained between 0.01 and $1 \mathrm{mg}$ titanium per serving. ${ }^{5} \mathrm{~A}$ study in the Netherlands, based on information from industry, identified mainly baked goods, desserts and sauces as products with the highest $\mathrm{E} 171$ content. $^{6}$

\section{Nanoparticles in E 171 - current research results}

$\mathrm{TiO}_{2}$ is used to make food appear whiter and colours appear shinier. To achieve this aesthetic effect, it has to scatter or reflect visible light. Manufacturers state that the particles must have a diameter of more than $100 \mathrm{~nm} .{ }^{8} \mathrm{In}$ the case of foodgrade $\mathrm{TiO}_{2}$, however, the particles are actually present in a size distribution, i.e. they are not al of the same size and some are less than $100 \mathrm{~nm}$ in size, i.e. in the nanoparticulate range.

Electron microscopic examinations of an E 171 sample from a large Italian supplier of food-grade $\mathrm{TiO}_{2}$ showed an average particle size of $110 \mathrm{~nm}$ and a wide size distribution ranging from 30 to $400 \mathrm{~nm}$. The proportion of nanoparticles smaller than $100 \mathrm{~nm}$ in this sample was approx. $\mathbf{3 6} \% .^{5}$

A further study examined five samples of $E 171$ (four samples anatase, one sample a mixture of anatase and rutile). ${ }^{9}$ Four samples came from Chinese manufacturers who also deliver to Europe, and one sample came from an Italian supplier. The samples contained between 17 and $35 \%$ nanoparticles. All samples also contained small amounts of phosphorus, aluminium and silicon. $\mathrm{SiO}_{2}$ and $\mathrm{Al}_{2} \mathrm{O}_{3}$ were found in concentrations of $0.13 \%$ to $1.5 \%$ of the dry weight and were therefore below the maximum limit in accordance with EU Regulation No. 231/2012. A sample from China featured surface modification with $\mathrm{Al}_{2} \mathrm{O}_{3}$ similar to that found in $\mathrm{TiO}_{2}$ when used in sunscreens to reduce photocatalytic activity. The authors are of the opinion that the traces of phosphorus, aluminium and silicon are not impurities but indications for specific surface modification (coating) of the particles.

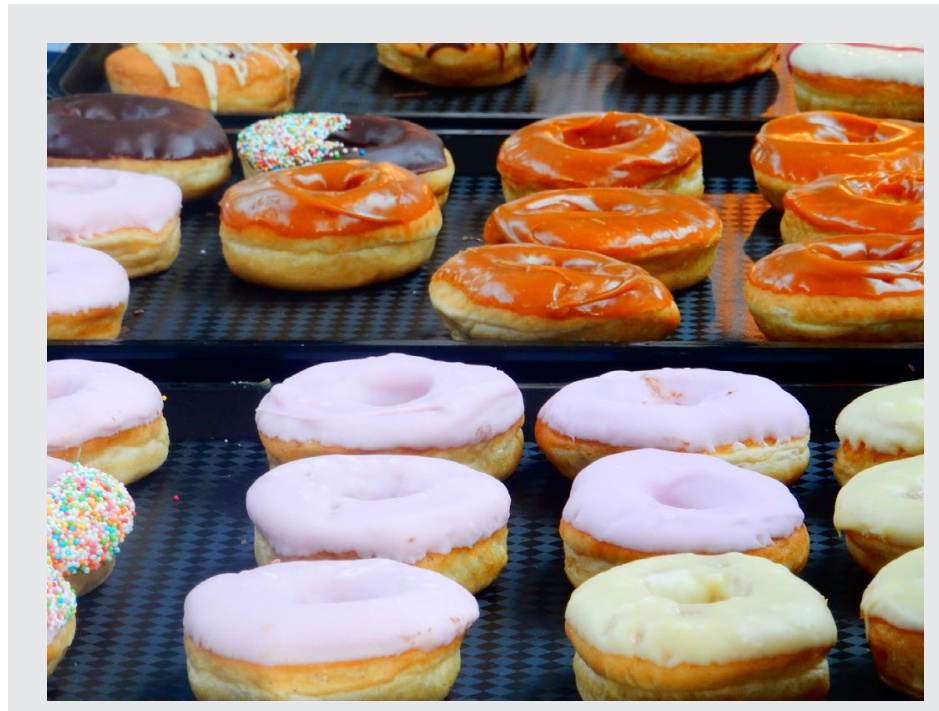

Figure 1:

$\mathrm{TiO}_{2}$ is used, for example, for sugar coatings for desserts (Source: Pexels on Pixabay).
To better characterise the particle size, three European manufacturers responded to an EFSA call and provided data on six E 171 products (five anatase, one rutile). ${ }^{10}$ The anatase products had an average particle diameter of 104 to $166 \mathrm{~nm}$, the proportion of nanoparticles below $100 \mathrm{~nm}$ ranged from 11.4 to $45.6 \%$. The rutile sample had an average diameter of $151 \mathrm{~nm}$ and the proportion of nanoparticles was $5.4 \%$. The manufacturers also stated that $E 171$ is not subjected to any surface modification or coating.

A Belgian research group examined 15 samples of $E 171$ from different European countries. The mean particle diameter in these samples was between 83 and $125 \mathrm{~nm}$ and the proportion of particles $<100 \mathrm{~nm}$ ranged between 32 and $59 \%$. 12 of the samples examined contained more than $50 \%$ nanoparticles. The authors of the studies emphasize that the methods of analysis have not yet been standardised and that sample preparation can have an influence on the measurement results. ${ }^{11}$

So far, only one study characterised E 171 both as it could be detected in finished products (confectionery) and as an original additive itself that was used in these products. ${ }^{12}$ In the samples of E 171 used as an additive, the size distribution was $10-350 \mathrm{~nm}$ with a median of 101 to $139.5 \mathrm{~nm}$. The proportion of particles $<100 \mathrm{~nm}$ was 23.6 to $49.3 \%$; a proportion that is in line with the results of other studies. The examination of the confectionery samples showed that one product - sweets with a liquorice filling - had the largest proportion of nanoparticulate E 171 (66\%), whereas the corresponding sample of the E $171 \mathrm{ex}$ tract only showed a nanoparticle proportion of $32.4 \%$. For the other confectionery products, the proportion of nanoparticles corresponded primarily to that of the additive used. The results of the study show that sample preparation, such as the extraction process from the finished products, can have an influence on the size distribution of the particles. Validated and harmonised methods for sample preparation prior to characterisation are therefore necessary in order to be able to compare study results.

The German consumer organisation Foodwatch examined four products from a manufacturer for the nanoparticulate proportion of E 171 used in these products. A baking mix contained $\mathbf{2 2} \%$, a decoration product $\mathbf{3 3} \%$, a ready-made icing $42 \%$, and another decorative product even $100 \%$ nanoparticles. ${ }^{13}$ There is no information on the methods of analysis in the Foodwatch background paper. The result of the investigation of the product with $100 \%$ E 171 nanoparticulate content suggests that - as already shown in a study cited above - the sample preparation can have a significant influence on the size distribution of the particles in the end product. 
In any case, the studies to date show that $\mathrm{TiO}_{2}$ for use in food is not a qualitatively uniform product of the chemical industry, but that its composition can differ depending on the manufacturer. This applies to the crystalline form (anatase, rutile or a mixture of both), the size distribution or the proportion of nanoparticles as well as the content of other chemical substances that are used during the manufacturing or for surface modification. According to the results of previous studies, the proportion of nanoparticles in E 171 can be up to $59 \%$. This is important because it is precisely this nanoparticulate fraction that is increasingly associated with health risks.

\section{Health risks from E 171}

The first and only risk assessment of $\mathrm{TiO}_{2}$ as a food additive was carried out by an expert committee of the Food and Agriculture Organization of the United Nations (FAO) and World Health Organization (WHO) (Joint FAO/WHO Expert Committee on Food Additives, JECFA) in 1969. ${ }^{14}$ The panel's conclusions at that time were that there was neither significant absorption nor storage in the tissue after oral intake and that establishing an ADI value did not appear necessary. The risk assessment was carried out on the basis of only five publications. These showed no significant effects in animal studies. ${ }^{15}$

In 1979, toxicologists from the National Cancer Institute (USA) carried out the first large-scale study on rats and mice on the carcinogenicity of $\mathrm{TiO}_{2}$ as a food additive. From the results, the experts concluded that oral intake of $\mathrm{TiO}_{2}$ was not carcinogenic for rats and mice. ${ }^{15}$

In his review, Jovanovic (2015) 4 summarised 16 studies from the years 1994 to 2014 investigating the toxic effects of $\mathrm{TiO}_{2}$ on mice and rats after oral administration. The diameter of the primary particles of the $\mathrm{TiO}_{2}$ used was 5 to $475 \mathrm{~nm}$. Unfortunately, the review does not state whether it is food-grade $\mathrm{TiO}_{2}$. With the exception of one study, all indicated toxic effects in the animals examined, for example liver or kidney damage, inflammatory reactions, and changes in the spleen and heart. Most studies also found bioaccumulation in the liver and spleen. The author comes to the conclusion that there is convincing evidence that $\mathrm{TiO}_{2}$ can be absorbed through the intestinal tract of mammals and that it can bioaccumulate in the tissues of mammals and other vertebrates. The studies showed that the spleen, liver, and kidneys are the organs most affected. $\mathrm{TiO}_{2}$ can cause histopathological and physiological changes in various organs depending on the dose. $\mathrm{TiO}_{2}$ would only be eliminated to a limited extent. The author also points out, however, that most of the studies were carried out with very high amounts of $\mathrm{TiO}_{2}$, which are well above the estimated intake levels for humans. The author also criticises the fact that studies are often carried out without precise particle characterisation.

Winkler et al. (2018) summarised the literature on toxicokinetics and toxicology of $E 171$ available up until 2017 and identified data gaps and uncertainties regarding the safety of this food additive. ${ }^{16}$ Health risks from long-term oral exposure to $\mathrm{TiO}_{2}$ cannot be ruled out; especially the liver can be affected negatively. The intake of $\mathrm{TiO}_{2}$ through food should, in any case, be less than $0.4 \mathrm{mg} / \mathrm{kg}$ body weight and day.

Schober et al. (2017) investigated the toxicokinetics of titanium dioxide. Five subjects received a single oral dose of $45 \mathrm{mg}$ nano- or microscale $\mathrm{TiO}_{2}$ dispersed in demineralised water. The study does not state whether this was food-grade $\mathrm{TiO}_{2}$. Blood analyses showed that both nanoscale $\mathrm{TiO}_{2}$ ( $8 \mathrm{~nm}$ particle diameter) and microscale $(190 \mathrm{~nm}$ particle diameter) were equally poorly absorbed into the bloodstream via the intestine. The blood concentrations fluctuated mainly within the dietrelated fluctuation range during the observation period. No significant increase in the amount of titanium was found in the subjects' urine. The authors conclude that orally administered $\mathrm{TiO}_{2}$ in all grain sizes is mainly excreted in the faeces. ${ }^{17}$

One study showed that nanoparticulate $\mathrm{TiO}_{2}$ could potentially have negative effects on people suffering from inflammatory bowel disease. ${ }^{18}$ Mice ( 3 groups of 12 animals each) in which coIon inflammation (colitis) had been triggered by oral administration of sodium dextran sulphate (DSS) received either only water or a suspension of $\mathrm{TiO}_{2}$ nanoparticles (50 or $500 \mathrm{mg}$ per day and $\mathrm{kg}$ body weight) via oral gavage or the drinking water. It was found that $\mathrm{TiO}_{2}$ nanoparticles aggravated colitis and also accumulated in the spleen. The authors of the study interpret the results as an indication that people with a defective intestinal barrier, as can be found in inflammatory bowel disease, may be negatively affected by the use of $\mathrm{TiO}_{2}$ nanoparticles.

An Australian study from 2019 examined the influence of $E 171$ on the intestinal flora of mice. ${ }^{19}$ For this purpose, the animals were given the food additive in amounts between 2 to $50 \mathrm{mg} / \mathrm{kg}$ body weight per day in the drinking water over a period of 3-4 weeks. It was found that E 171 only slightly changed the composition of the intestinal flora, but that the immune system's function responsible for stabilising and regulating the intestinal flora was significantly impaired and inflammation occurred. The authors conclude that longterm exposure to $\mathrm{E} 171$ can predispose for conditions such as inflammatory bowel disease and colon cancer.
In 2017, the French National Institute of Agricultural Research (INRA) carried out a study with E 171 on rats. The study was funded by a research programme of the French ANSES. Bettini et al. (2017) ${ }^{20}$ administered E 171 (with a proportion of $44.7 \%$ nanoparticles) to test animals that had previously been injected with a chemical substance that promotes the development of tumours (tumour promoter) via a stomach tube for seven days or via the drinking water for 100 days in amounts corresponding to human exposure. Effects on the immune system and changes in the intestinal mucosa were found. In addition, certain inflammatory parameters were elevated and it was shown that $\mathrm{E} 171$ can trigger changes in the intestine via oral intake, which can be interpreted as precancerous stages. This study in particular prompted the French government to ban E 171 for one year starting from 01.01.2020 (see below)

$\mathrm{TiO}_{2}$ is not soluble in water and the particles' surface can be altered by components of the food, which can change their behaviour. Unlike in the French study mentioned above, Blevins et al. (2019) examined possible acute and sub-chronic immunological effects as well as negative effects on the intestines of rats, in which $E 171$ was not administered in the drinking water or by gavage, but with the feed. There were no effects on the immune system or the tissue morphology in the animals examined, even in the group which had been administered the highest dose. The authors conclude that the food matrix in which $\mathrm{E} 171$ is embedded might be one important determinant for toxicity. This is also confirmed by a study by Zhang et al. (2019), which showed that the selected food simulant ${ }^{21}$ reduced the cell toxicity of $\mathrm{TiO}_{2}$ nanoparticles in vitro more than 5 -fold. ${ }^{22}$

\section{Safety assessment by EFSA}

Regulation (EU) No. 257/2010 of 25 March 2010 stipulated that all food additives approved in the EU before 20 January 2009 must be subjected to a safety re-evaluation. The EFSA completed the assessment of $E 171$ in June 2016 and came to the conclusion in its statement that, based on the available data, $\mathrm{TiO}_{2}$ as a food additive is harmless in terms of genotoxicity and not carcinogenic when ingested. ${ }^{7}$

With regard to possible negative effects on the reproductive system, the EFSA was unable to draw any final conclusions because of insufficient data. This would require a 90-day study, as specified in the EFSA guidelines ${ }^{23}$ on data requirements for applications for authorisation of a food additive, or a multi-generation or extended onegeneration reproductive toxicity study (EOGRTS; OECD test guideline 433). For this reason, no ADI value could be determined. The EFSA found 
that, based on the estimated exposure of consumers and the established no-observed-adverse-effect level (NOAEL) value of $2250 \mathrm{mg} / \mathrm{kg}$ body weight/day, the margin of safety (MOS) was over 100 and therefore sufficient.

\section{The ban on E 171 in France}

France banned the use of $\mathrm{TiO}_{2}$ as a food additive from 01 January 2020 for an initial period of one year. ${ }^{24}$ The basis for this decision is a statement by ANSES. ${ }^{25}$ The main reason for this ban are uncertainties regarding possible negative health effects on consumers, in particular because of E 171's nanoparticulate content.

Since 2006, ANSES has carried out a number of activities relating to nanomaterials in food, animal feed, consumer products, and employee protection. The authority advocates that suitable protocols are developed for toxicological studies (clear physico-chemical characterisation, detailed and reproducible protocols, etc.) and exposure studies in order to be able to assess health risks from products with nanomaterials. ANSES also recommends limiting exposure of workers, consumers and the environment, particularly by promoting safe products without nanomaterials. If hazards for human health or the environment are identified, ANSES recommends weighing the benefits of products with nanomaterials for consumers and clearly demonstrating their benefits. ${ }^{26}$

ANSES acknowledged that the study carried out by Bettini et al. $(2017)^{20}$ (see above) does not make it possible to draw definitive conclusions on the health effects of $\mathrm{TiO}_{2}$ on humans, nor does it call into question EFSA's 2016 assessment. However, the authority emphasised that this study showed effects that had not been identified yet, in particular E 171's possible carcinogenic potential. Therefore, ANSES requested in 2017 that further studies be carried out to be able to estimate possible health effects associated with the oral intake of E $171 .{ }^{26}$

In February 2019, the French ministries for the economy, health, agriculture and the environment commissioned ANSES to analyse the latest studies on the toxicity of $E 171$. A group of experts from ANSES identified and analysed 25 new studies that had been published since 2017 . ANSES summarises its conclusions as follows: ${ }^{25}$

- Studies on the physico-chemical characterisation in food simulants and in biological test media show that $\mathrm{TiO}_{2}$ remains biologically stable in the digestive tract, and that the formation of a corona (biomolecule shell) as a result of the adsorption of food matrix components changes the surface properties of the $\mathrm{TiO}_{2}$ particles and can affect their fate in vivo.
- Studies on the interaction between $\mathrm{TiO}_{2}$ particles and certain bacterial strains in vitro show no evidence that $E 171$ can significantly change the intestinal flora after ingestion. However, these studies were only carried out in vitro and do not comprehensively reflect the complexity of the intestinal flora. In vivo, exposure to E 171 may not lead to substantial qualitative or quantitative changes in the mucus $^{27}$.

- Studies on the fly genus Drosophila have shown developmental defects of non-genetic origin after oral ingestion of amounts of E 171 corresponding to human exposure.

- Studies carried out ex vivo on segments of human subcutaneous arteries and in rats have shown that high levels of E 171 can induce cardiovascular effects that may lead to high blood pressure and heart failure.

- The latest in vitro studies on genotoxicity do not provide any new evidence but confirm DNA damage from oxidative stress caused by $\mathrm{TiO}_{2}$. However, the latest studies do not exclude the possibility of a direct effect of $\mathrm{TiO}_{2}$ on the DNA and/or the spindle apparatus of a nuclear division spindle that could be causing DNA damage.

- Carcinogenicity studies report changes in gene expression as well as epigenetic effects.

Some of the 25 new studies analysed provide new evidence. However, none of the new studies could confirm or refute the potential carcinogenic effect of $E$ 171, which was shown in the study by Bettini et al. $(2017)^{20}$. Since there are still uncertainties, ANSES recommends a precise physico-chemical characterisation of $E 171$, better characterisation of possible E 171 hazards, and an assessment of the justification for its use, i.e. there must be clear advantages.

Since better characterisation of the dangers and risks posed by E 171 is still pending, ANSES reiterated in 2019 its earlier conclusions on nanomaterials, which entail limiting the exposure of workers, consumers and the environment as part of a step-by-step process, primarily by promoting safe products that are equivalent in terms of function and effectiveness and do not contain nanomaterials.

\section{EFSA opinion on new studies}

The results of the study by Bettini et al. (2017) 20 also prompted the European Commission to commission the EFSA to analyse these and other more recent studies.
With regard to the study by Bettini et al. (2017), the EFSA criticised the following points in $2018^{28}$.

- The particles of the $\mathrm{TiO}_{2}$ test material were coated with bovine serum albumin (BSA) and subjected to ultrasound treatment. This test protocol was designed to prevent agglomeration of the nanoparticles and was specifically developed for hazard identification of nanoparticles in suspension. With regard to the observed effects on the immune system, the EFSA notes that the BSA coating of the particles itself can cause an immunological or allergic reaction.

- The administration of $\mathrm{TiO}_{2}$ by gavage or drinking water is not fully representative of the use of $E 171$ as a food additive. Since interactions with the food matrix may not occur, these procedures could lead to uncertainties when extrapolating the results of this study to the evaluation as a food additive.

- Only a single biomarker was used (preneoplastic lesions of the colon)

- The initiating potential of $\mathrm{TiO}_{2}$ for changes in the intestine, which can be interpreted as precancerous stages (aberrant crypt foci, $\mathrm{ACF}^{29}$ ), was not observed in a further study. ${ }^{30}$

- An earlier publication showed that the number of ACFs triggered by various food compounds is not suitable for predicting the final number of intestinal tumours. The authors of this study do not consider the number and size of ACFs as suitable biomarkers for colorectal cancer. 31

The EFSA considers the results of Bettini et al. $(2017)^{20}$ not sufficient for concerns that E 171 could trigger or promote colon cancer.

The EFSA analysed three other studies ${ }^{32}$ and came to the following conclusions:

The results of the study by Bettini et al. (2017) $)^{20}$ do not provide enough justification for a new carcinogenicity study. However, should additional information become available, this could be reconsidered in the future.

The new results in the study by Proquin et al. $(2017)^{20}$ do not change the conclusion regarding the genotoxicity of $\mathrm{TiO}_{2}$ as stated in the EFSA opinion from 2016

The effects of synthetic $\mathrm{TiO}_{2}$ nanoparticles reported by Guo et al. (2017) ${ }^{32}$ are of uncertain biological importance and therefore of limited relevance for a risk assessment of $\mathrm{TiO}_{2}$ as a food additive. 
There are significant uncertainties in the risk assessment carried out by Heringa et al. (2016) ${ }^{32}$ because the evidential value of the data was not analysed.

The four studies provide information, but are fraught with uncertainties. Therefore, their relevance for a risk assessment is considered limited and further research is necessary to reduce the level of uncertainty.

In general, three of the four studies were able to show that $\mathrm{TiO}_{2}$ can trigger various effects in vitro and in vivo. These studies are useful for hazard identification. The EFSA recommends carrying out an extended one-generation reproductive toxicity study and further studies in which E 171 is administered in a food matrix.

\section{Positions of institutions, NGOs and industry}

In September 2019, the German Federal Institute of Risk Assessment (BfR) reviewed the ANSES report and came to the conclusion that no scientific arguments could be identified that would justify calling into question the 2016 EFSA opinion on the use of titanium dioxide as a food additive. ${ }^{33}$

The Titanium Dioxide Manufacturers Association claims that $\mathrm{E} 171$ is an approved food additive which complies with applicable European legislation, i.e. it does not contain any substances that are considered dangerous to consumers. E 171 is the most effective white colour in food and is even five times more effective than alternatives such as silicon dioxide or calcium carbonate. Replacing it with an alternative could also bring new, unexplored risks. ${ }^{34}$ The ban on E 171 prompted the European Commission to develop options for a joint approach within the European Union. An extension of the ban to the entire EU is currently being discussed. This would mean a tempo- rary suspension of marketing foods that contain E 171 or introducing measures to reduce the exposure of vulnerable groups of consumers, such as for instance children, by withdrawing the authorisation for certain food groups. However, Food Federation Germany fears this would have serious economic consequences. Companies in the supply and manufacturing sector would have to carry out the necessary expensive and complex processes of reformulating products. This would be particularly time-consuming according to Food Federation Germany as it is technically difficult to replace $\mathrm{TiO}_{2}$ with a suitable alternative because of its functionality. ${ }^{35}$

In May 2019, the German television station "Das Erste" devoted a programme to the topic of titanium dioxide and conducted a survey amongst the 15 largest confectionery producers in Germany. This showed that some manufacturers in Germany have already changed their recipes, and others announced that they want to change their production. 36

With reference to the ban in France, European consumer and environmental protection organisations are calling on the European Commission to remove $\mathrm{E} 171$ from the list of permitted food additives on the basis of the precautionary principle as all Europeans have the same right to a high level of protection. In addition, no objections should be raised or actions taken against the French measure. ${ }^{37}$

\section{Notes and References}

1 Fries R. \& Simkó M. (2012): (Nano-)Titanium dioxide (Part I): Basics, Production, Applications. NanoTrust Dossier No. 033en, November 2012.

2 Roper M-H., Terrisse HI., Mercier-Bonin M. \& Humbert B. (2017): Titanium Dioxide as Food Additive. Intech.

3 https://www.zusatzstoffe-online.de/ information/667.doku.htm|\#Trennmittel. Accessed 15.04.2020.

\section{Conclusion}

Titanium dioxide has been used as a food additive for many decades and has long been considered safe for human health. In recent years, however, the considerable proportion of nanoparticles in $\mathrm{TiO}_{2}$ has led to an increase in studies on toxicokinetics and toxicology. Some of these studies give rise to concerns about health risks, but are fraught with uncertainty and prove insufficient for a comprehensive risk assessment. Evidence of a possible carcinogenic potential of $\mathrm{TiO}_{2}$ as a food additive in animal studies has led the French government to ban it for one year until further investigations are available. This measure appears justified as children in particular, because of their higher consumption of sweets, consume a particularly large amount of $\mathrm{TiO}_{2}$; especially in view of this food additive being used exclusively for aesthetic purposes without having any other benefit for the consumer. However, the industry emphasises that $E 171$ would not be harmful to health and fears that the ban would have considerable disadvantages.

4 Jovanovic B. (2015): Critical Review of Public Health Regulations of Titanium Dioxide, a Human Food Additive. Integrated Environmental Assessment and Management, Vol. 11(1): 10-20.

5 Weir A., Westerhoff P., Fabricius L. \& v. Goetz, N. (2012): Titanium Dioxide Nanoparticles in Food and Personal Care Products. Environ. Sci. Technol. 2012; 46(4): 2242-2250.

6 RIVM (2015): Exposure assessment of the food additive titanium dioxide (E 171) based on use levels provided by the industry. RIVM Letter report 2015-0195.

7 EFSA (2016): Re-evaluation of titanium dioxide (E 171) as food additive. EFSA Journal 2016; 14(9):4545. https://efsa.onlinelibrary.wiley.com/doi/ 10.2903/j.efsa.2016.4545Accessed 16.11.2020.

8 TDMA - Titanium Dioxide Manufacturers Association. https://tdma.info/de/titandioxid-inlebensmitteln/. Accessed 15.04.2020.

9 Yang Y., Doudrick K., Bi X., Hristovski K. Herckes P., Westerhoff P. \& Kaegi R. (2014): Chracterization of Food-Grade Titanium Dioxide: The Presence of Nanosized Particles. Environ. Sc.i Technol. 2014; 46: 6391-6400.

10 EFSA (2019): Scientific Opinion on the proposed amendment of the EU specifications for titanium dioxide (E 171) with respect to the inclusion of additional parameters related to its particle size distribution. EFSA Journal 2019; 17(7):5760.

11 Verleysen E., Waegeneers N., Brassinne F. De Vos S., Jimenez I.O., Mathioudaki S. \& Mast J. (2020): Physicochemical Characteriziation of the Pristine E171 Food Additive by Standardized and Validated Methods. Nanomaterials 2020, 10, 592. https://res.mdpi.com/d attachment/nanomaterials/ nanomaterials-10-00592/article deploy/nano materials-10-00592.pdf. Accessed 16.11.2020.

12 Geiss O., Ponti J., Senaldi Ch., Bianchi I., Mehn D. Barrero J., Gilliland D., Matissek R. \& Anklam E. (2020): Characterisation of food grade titania with respect to nanoparticle content in pristine additives and in their related food products. Food Additives \& Contaminants: Part A., Vol. 37, No. 2: 239-253. https://www.tandfonline.com/doi/pdf/10.1080/194 40049.2019.1695067? needAccess=true. Accessed 16.11.2020.

13 Foodwatch Background Paper: https://www. foodwatch.de/fileadmin/-DE/Themen/Titandioxid/ Dokumente/2019 0829 Hintergrundpapier Titandioxid.pdf. Accessed 14.04.2020.

14 Joint FAO/WHO Expert Committee on Food Additives (1970): Specification for the identity and purity of food additives and their toxicological evaluation. Some food colours, emulsifiers, stabilizers, anticaking agents, and certain other substances. Thirteenth Report of the Joint FAO/ WHO Expert Committee on Food Additives, Rome 27 May-4 June 1969. World Health Organization technical report series no. 445, FAO nutrition meetings report series no. 46. Geneva.

15 For sources see Jovanovic (2015): Endnote 4.

16 Winkler H.Ch., Notter T., Meyer U. \& Naegeli H. (2018): Critical review of the safety assessment of titanium dioxide additives in food. J. Nanobiotechnol. (2018) 16:51. https://www.ncbi.nlm.nih gov/pmc/articles/PMC5984422/pdf/12951_2018_ Article 376.pdf. Accessed 16.11.2020. 
17 Schober W., Matzen W., Winterhalter R., Sysoltseva M. \& Fromme H. (2017): Integrative Lebensmittelsicherheit: Ein kombinierter Ansatz aus Analytik und Humanbiomonitoring zur Verbesserung der Risikovorsorge am Beispiel nanopartikulärer Kontaminanten. J Consum Prot Food Saf (2017) 12:99-103.

${ }^{18}$ Ruiz P.A., Morón B., Becker H.M., Lang S., Atrott K., Spalinger M.R., Scharl M., Wojtal K., FischbeckTerhalle A., Frey-Wagner I., Hausmann M., Kraemer T. \& Rogler G. (2017): Titanium dioxide nanoparticles exacerbate DSS-induced colitis: role of the NLRP3 inflammasome. Gut 2017; 66:1216-1224.

19 Pinget G., Tan J., Janac B., Kaakoush N.O., Angelatos A.S., O'Sullivan J., Koay Y.Ch., Sierro F., Davis J., Divakaria S.K., Khanal D., Moore R.J., Stanley D., Chrazanowski W. \& Macia L. (2019): Impact of the Food Additive Titanium Dioxide (E171) on Gut Microbiota-Host Interaction. Frontiers in Nutrition, Vol. 6, Article 57.

20 Bettini S., Boutet-Robinet E., Cartier C., Coméra C., Gaultier E., Dupuy J., et al. (2017): Food-grade $\mathrm{TiO}_{2}$ impairs intestinal and systemic immune homeostasis, initiates preneoplastic lesions and promotes aberrant crypt development in the rat colon. Scientific Reports; 7:40373.

${ }^{21} \mathrm{~A}$ food simulant is a chemical substance with similar characteristics like the different food categories (aqueous, acidic, alcoholic foods, dairy and cheese products, oily, fatty and dry foods). https://www.reflexx.com/de/faq/was-ist-einlebensmittelsimulanzl. Accessed 16.11.2020.

22 Zhang Z., Zhang R., Xiao H., Bhattacharya K., Bitounis D., Demokritou P. \& Mc Clements D.J. (2019): Development of standardized food model for studying the impact of food matrix effects on the gastrointestinal fate and toxicity of ingested nanomaterials. Nanolmpact 13 (2019):13-25.

${ }^{23}$ EFSA (2012): Scientific Opinion. Guidance for submission for food additive evaluations, EFSA Journal 2012;10(7):2760.
24 https://www.gouvernement.fr/l-additif-e171-serainterdit-a-partir-du-1er-janvier-2020. Accessed 15.04.2020.

25 ANSES (2019): Opinion of the French Agency for Food, Environmental and Occupational Health \& Safety on the risks associated with ingestion of the food additive E171. https://www.anses.fr/en/ system/files/ERCA2019SA0036EN.pdf. Accessed 15.04.2020.

26 https://www.anses.fr/en/content/titanium-dioxidenanoparticles-food-additive-e171-biological-effectsneed-be-confirmed. Accessed 15.04.2020.

27 A protective barrier formed by the cells of the intestinal mucosa.

28 EFSA (2018): Evaluation of four new studies on the potential toxicity of titanium dioxide used as food additive (E 171). EFSA Journal 2018;16(7): 5366

29 "Aberrant crypt foci (ACF) are clusters of abnorma tube-like glands in the lining of the colon and rectum. Aberant crypt foci form before colorectal polyps and are one of the earliest changes seen in the colon that may lead to cancer. [...] The relevance of ACF as a surrogate endpoint biomarker for cancer is controversial." https://en.wikipedia.org/ wiki/Aberrant_crypt_foci. Accessed 15.04.2020.

30 Urrutia-Ortega I.M., Garduno-Balderas L.G., Delgado-Buenrostro N.L., Freyre-Fonseca V., Flores-Flores J.O., Gonazales-Robles A., Pedraza Chaverri J., Hernandes-Pando R., RodriguezSoza M., Leon-Cabrera S., Leon-Terrazas L., van Loveren H. \& Chirino Y.I. (2016): Food-grade titanium dioxide exposure exacerbates tumor formation in colitis associated cancer model. Food and Chemical Toxicology, 93:20-31.

31 Wijnands M.V.M., van Erk M.J., Doornbos R.P. Krul C. \& Wouterson R.A. (2004): Do aberant crypt foci have predictive value for the occurrence of colorectal tumours? Potential of gene expression profiling in tumours. Food and Chemical Toxicology, 42: 1629-1639.
32 Proquin H. et al. (2017): Titanium dioxide food additive (E 171) induces ROS formation and genotoxicity: contribution of micro- and nano-sized fractions. Mutagenesis, 32: 139-149.

Guo Z. et al. (2017): Titanium dioxide nanoparticle ingestion alters nutrient absorption in an in vitro model of the small intestine. Nanolmpact, 5: 70-82. Heringa M.B. et al. (2016): Risk assessment of titanium dioxide nanoparticles via oral exposure, including toxicokinetic considerations. Nanotoxicology, 10(10): 1515-1525.

33 Bundesinstitut für Risikobewertung (BfR), 26. September 2019: Titandioxid - es besteht noch Forschungsbedarf. https://www.bfr.bund.de/ $\mathrm{cm} / 343 /$ titandioxid-es-besteht-nochforschungsbedarf.pdf. Accessed 15.04.2020.

34 https://tdma.info/de/titandioxid-in-lebensmitteln/. Accessed 15.04.2020.

35 Letter from the Food Federation Germany to the Federal Ministry of Food and Agriculture (Bonn) on the 05.09.2019. https://www.foodwatch.org/ fileadmin/-DE/Themen/Titandioxid/Dokumente/ 2019 Schreiben BLL VCl Titandioxid geschw. pdf. Accessed 15.04.2020.

36 https://www.daserste.de/information/wirtschaftboerse/plusminus/sendung/hr/streit-umtitandioxid-100.html. Accessed 15.04.2020.

37 Letter of European consumer protection organizations to Vice-president Jyrki Katainen of the European Commission on the 03.05.2019. https://mk0eeborgicuypctuf7e.kinstacdn.com/wpcontent/uploads/2019/07/Letter-E171-Tio2May-19.pdf. Accessed 15.04.2020.

\section{MASTHEAD}

Owner: Austrian Academy of Sciences; legal person under public law (BGBI 569/1921 idF BGBI I 31/2018);

Dr. Ignaz Seipel-Platz 2, A-1010 Vienna

Editor: Institute of Technology Assessment (ITA); Apostelgasse 23 A-1030 Vienna; www.oeaw.ac.at/ita

Mode of publication: The NanoTrust Dossiers are published irregularly and contain the research results of the Institute of Technology Assessment in the framework of its research project NanoTrust. The Dossiers are made available to the public exclusively via the Internet portal "epub.oeaw": epub.oeaw.ac.at/ita/nanotrust-dossiers/

NanoTrust-Dossier Nr. 055en, December 2020: epub.oeaw.ac.at/ita/nanotrust-dossiers/dossier055en.pdf

ISSN: 1998-7293

This Dossier is published under the Creative Commons (Attribution-NonCommercial-NoDerivs 2.0 Austria) licence: creativecommons.org/licenses/by-nc-nd/2.0/at/deed.de 